\title{
High-throughput sensing microtiter plate for determination of biogenic amines in seafood using fluorescence or eye-vision $\dagger$
}

\author{
H. A. Azab, ${ }^{a}$ S. A. El-Korashy, ${ }^{a}$ Z. M. Anwar, ${ }^{a}$ G. M. Khairy, ${ }^{a}$ Mark-Steven Steiner ${ }^{b}$ and Axel Duerkop ${ }^{* b}$ \\ Received 20th January 2011, Accepted 12th August 2011 \\ DOI: 10.1039/c1an15049a
}

\begin{abstract}
A new optical sensing microplate was developed for rapid screening for the presence of biogenic amines (BAs) in seafood samples with high sensitivity. The deposition of a sensing spot (containing a chameleon dye (Py-1) in a polymeric cocktail) on the bottom of the wells of a standard microplate renders the plate a new sensing tool for a rapid and parallel detection of up to 96 (real) samples. This sensing microplate enables (1) a semi-quantitative readout of analyte concentration by eye-vision, (2) a rapid fluorescence readout of 96 samples with standard instrumentation in less than two minutes (unlike chromatographic and electrophoretic methods), (3) a statistically robust data evaluation (with $8-12$ replicates) and (4) a rapid parallel sample preparation with standard 8 or 12-channel

micropipettes. On reaction with biogenic amines, the dye shows a significant visible color change from blue over green to red color. The appearance of red color favorably coincides with the concentration of BAs that can induce symptoms of poisoning. The linear ranges of fluorescence calibration data for six biogenic amines cover the clinical toxicological relevant range of BAs that is too low to be detected by the human nose. The LODs range from 0.16 to $0.56 \mu \mathrm{g} \mathrm{mL} \mathrm{m}^{-1}$, with correlation coefficients $\left(r^{2}\right)$ between 0.985 and 0.999 . Finally, the evolution of spoilage of four fish samples (monitored by determination of their BA status) and the increase of their total amine content were found to agree well with previous data on time-dependent evolution of BAs in fish.
\end{abstract}

\section{Introduction}

Biogenic amines (BAs) are natural nutrition constituents and are important from a hygienic point of view as they can induce food poisoning and are able to initiate various pharmacological reactions. Histamine (his), putrescine, cadaverine, tyramine, and spermidine are considered to be the most important biogenic amines occurring in foods. ${ }^{1,2}$ The term biogenic originates from the fact that they are formed by the action of bacteria which induce the decarboxylation of amino acids. ${ }^{3}$ Histamine has been found to be the origin of food poisoning in several cases, while hypertensive crisis was related to the action of tyramine. ${ }^{4-6}$ The pharmacological effects of biogenic amines range from excitation of the smooth muscles (of the uterus, the intestine and the respiratory tract) to peripheral vasoconstriction, increase of cardiac output, migraine and paresis of the extremities. ${ }^{7}$ Another detrimental effect is the enhancement of the toxicity of histamine in the presence of, e.g., cadaverine, putrescine, and tyramine. ${ }^{8,9}$

${ }^{a}$ Chemistry Department, Faculty of Science, Suez Canal University, 41522 Ismailia, Egypt

${ }^{b}$ Institute of Analytical Chemistry, Chemo- and Biosensors, University of Regensburg, D-93040 Regensburg, Germany. E-mail: axel.duerkop@ chemie.uni-r.de

$\dagger$ Electronic supplementary information (ESI) available. See DOI: $10.1039 /$ clan15049a
Further on, biogenic amines containing additional secondary amine groups have carcinogenic potential due to their reactions with nitrites to form nitrosamines. Biogenic amines have been determined in various types of foods like in cheese, fish, meat, sauces, eggs and mushrooms. ${ }^{10-14}$ Several studies employ histamine to trace the freshness of fish, especially of mackerel whose muscle tissue is rich in free histidine. ${ }^{15}$ Most BA levels increase with storage time and this makes their concentration a good indicator for the freshness of food. These properties suggest their use as an indicator not only to determine the aging of food but also to control the purity of water and soil.

Several methods for histamine determination have been described, and particularly fluorimetry and liquid chromatography (LC) can be considered as the most common ones for determination of biogenic amines in food. ${ }^{16} \mathrm{~A}$ spectrofluorimetric method (in agreement with AOAC) was used for histamine determination in canned fish. ${ }^{17}$ Among the chromatographic methods, high performance liquid chromatography (HPLC), ${ }^{18}$ capillary electrophoresis (CE),${ }^{19}$ gas chromatography coupled with mass spectrometry (GC-MS), ${ }^{20}$ and thin-layer chromatography (TLC) can be mentioned. ${ }^{21}$ Furthermore, an enzyme sensor array for the simultaneous determination of three biogenic amines by pattern recognition using an artificial neural network was shown. ${ }^{22}$ The time required for analysis of biogenic amines using $\mathrm{GC}-\mathrm{MS}^{20}$ is $45 \mathrm{~min}$ per sample, $100 \mathrm{~min}$ per sample 
for HPLC, ${ }^{18} 150 \mathrm{~min}$ for TLC, ${ }^{21} 45 \mathrm{~min}$ per sample for $\mathrm{CE}^{19}$ and 23 min per sample for the enzyme sensor array. ${ }^{22} \mathrm{~A}$ disadvantage of the TLC, HPLC, CE and GC-MS analyses in general is the long and tedious sample pretreatment. In addition, the analysis time is long although precolumn derivatization is already included in the HPLC and CE analyses. A further principal drawback of these methods is the requirement of (sometimes harmful) organic solvents of HPLC grade quality, whereby the cost for their purchase and disposal has to be taken into consideration. Disposable screen-printed electrode biosensors with enzymes have been shown as a step forward to reduced sample pretreatment. ${ }^{23}$ Another approach uses a home-built reflectometric sensing system to monitor the total volatile amines in the headspace over fish samples. ${ }^{24,25}$ The color change shown at various $\mathrm{pH}$ has potential to be applied in food packaging sensors. A gas-mixing device required for calibration of these sensors is potentially not available in many labs. Hence, rapid and easy analytical methods working in standard microplates are attractive in order to adapt BA measurements to high throughput screening (HTS).

In this work, we sought to develop a high-throughput sensing microplate for the quantitation of biogenic amines in real samples (e.g. seafood) as a rapid screening tool prior to HPLC or other more time-consuming methods. The new sensing plate enables parallel and rapid (96 samples in $2 \mathrm{~min}$ ) detection of BAs (even by visible readout) with standard fluorescence equipment. The sensing plate further enables time-saving 8-12 channel parallelized sample preparation and thus contributes to a robust statistical evaluation of the fluorescence measurement. Upon reaction with biogenic amines, the blue and virtually non-fluorescent dye Py-1 is converted into a red conjugate which is strongly fluorescent $\left(\lambda_{\mathrm{em}}=620 \mathrm{~nm}\right) .{ }^{19}$ The change of color has the advantage that any unreacted (blue) label in the sample is not "seen" and not photoexcited by the excitation light of around 500 $\mathrm{nm}$. As an example, the total amount of biogenic amines was monitored in 4 seafood species (codfish, tuna, salmon and shrimp) at different stages of spoilage.

\section{Experimental}

\section{Materials}

Hypan HN 80 polymer was obtained from Hymedix Inc. (www. hymedix.com). Py-1 was from ActiveMotif Chromeon (www. activemotif.com). ${ }^{26}$ All other chemicals were purchased from Sigma (www.sigmaaldrich.com). They are as follows: spermidine, putrescine, histamine, tyramine, 1-tetradecylamine and benzylamine. The amines were of analytical grade and methanol was of chromatographic grade.

\section{Preparation of amine standard solutions}

Specific amounts of each of the amines were dissolved in $5 \mathrm{~mL}$ of methanol to obtain a primary stock solution of $10 \mathrm{mM}$ of amine as a free base. $1 \mathrm{~mL}$ of each amine primary stock solution was placed in a $10 \mathrm{~mL}$ volumetric flask and $80 \mu \mathrm{L}$ of trimethylamine were added to deprotonate traces of protonated BAs. The volume was completed to $10 \mathrm{~mL}$ with methanol to produce a secondary stock solution containing $1 \mathrm{mM}$ of each amine. Working standard solutions were prepared by transferring 4.5,
$22.5,45,90,135,180,225,270,315,360$ and $450 \mu \mathrm{L}$ of each secondary stock solution into a vial and completing the volume to $500 \mu \mathrm{L}$ with methanol in order to obtain amine concentrations of $1,5,10,20,30,40,50,60,70,80,100 \mu \mathrm{g} \mathrm{mL}^{-1}$, respectively. All solutions were stored at $4{ }^{\circ} \mathrm{C}$.

\section{Fabrication of sensing microtiter plates}

A 5\% (weight) solution of Hypan HN 80 in DMSO (e.g. $1 \mathrm{~g}$ Hypan $+19 \mathrm{~g} \mathrm{DMSO}$ ) is heated to $60^{\circ} \mathrm{C}$ for $12-24 \mathrm{~h}$ and stirred well until Hypan is dissolved completely and a clear yellowish solution is obtained. A Py-1 stock solution of $5 \mathrm{mg}$ of Py-1 in 1 $\mathrm{mL}$ of DMSO is made and stored at $4{ }^{\circ} \mathrm{C}$ in the dark. Subsequently, $10 \mu \mathrm{L}$ of Hypan HN 80 solution and $4 \mu \mathrm{L}$ of Py- 1 stock solution are injected into each well of a microtiter plate (no. 651001, 96 well microplates, V-bottom) from Greiner bio-one (www.gbo.com) and finally the plate is shaken in a round motion in an Eppendorf Thermomixer Comfort (www.eppendorf.com) for $30 \mathrm{~min}$ at $40{ }^{\circ} \mathrm{C}$ to obtain deep blue colored spots in the sensing microtiter plates as indicated in Fig. $\mathrm{S} 1 \uparrow$. Those plates are stored at $4{ }^{\circ} \mathrm{C}$ in the dark in a desiccator over solid $\mathrm{KOH}$ and were used for sensing within one week. They are stable for at least one month, whereby their stability was tested by photometric measurement of the blue sensing layer.

\section{Extraction of seafood samples}

Seafood samples were purchased from a local supermarket. $10 \mathrm{~g}$ of seafood sample were mixed with $100 \mathrm{~mL}$ of methanol in a beaker and homogenized with an IKA Ultraturrax (www.ika. com) at high speed for $2 \mathrm{~min}$. A portion of the homogenisate was transferred to a conical flask and placed in a $60{ }^{\circ} \mathrm{C}$ water bath for $30 \mathrm{~min}$ to yield a yellowish clear solution. This extract was filtered through a porcelain Buchner funnel with blue ribbon filter paper (Schleicher und Schüll: 58933, www.whatman.com) two or three times to yield samples free of visual particles. The sample was centrifuged for $15 \mathrm{~min}$ at $3500 \mathrm{rpm}$, if an oil fraction appeared on top of the methanol phase. After centrifugation, the oil phase was removed with a pipette. Then, $80 \mu \mathrm{L}$ of triethylamine were added and the sample was stored at $-18{ }^{\circ} \mathrm{C}$.

\section{Quantitation of BAs}

$50 \mu \mathrm{L}$ of the respective working standard solutions were transferred into each well of a sensing microtiter plate for quantitation of the amines. The measurement was performed at $\lambda_{\mathrm{ex}}=485 \mathrm{~nm}$ and $\lambda_{\mathrm{em}}=620 \mathrm{~nm}$ with a FLUOstar Optima microtiter plate reader (from BMG LABTECH, Offenburg, Germany, www. bmglabtech.com). A 10 min incubation time was adjusted and $5 \mathrm{~s}$ of shaking is recommended both before and at the end of the incubation time. The temperature was set to $25^{\circ} \mathrm{C}$. The gain of the microtiter plate reader was fixed at a value of 1550 . The mean fluorescence intensity was calculated as the average of five independent measurements of each concentration of BAs.

A standard addition method was used for quantitation of the amines in seafood. Increasing quantities of histamine $(5,10,20$, 30,40 and $50 \mu \mathrm{g} \mathrm{mL}^{-1}$ ) were added to the fish sample by transferring $22.5,45,90,135,180$ and $225 \mu \mathrm{L}$, respectively, of the 1 $\mathrm{mM}$ secondary stock solution of histamine to a diluted solution (see the column of dilution factors in Table 3) of extracted 
sample. The volume was filled to $500 \mu \mathrm{L}$ with methanol and 5 replicates of $50 \mu \mathrm{L}$ of each fish sample were injected into the sensing microtiter plate. Hence, pure methanolic solutions are analyzed in each well. Then, the plate was measured as described above.

\section{Results and discussion}

\section{Sensing plate, choice of dye and extraction method}

The most novel aspect of the concept presented here is the conversion of a standard microplate into a sensing tool for an optical assay of BAs by the deposition of a sensor spot in each well. This concept has many advantages: first, a semi-quantitative readout by eye-vision is possible, similar to commonly used test stripes. Second, a rapid fluorescence readout ( 96 samples) is possible with standard instrumentation in less than two minutes which is a huge advantage compared to chromatographic and electrophoretic methods (see Table 2). Third, statistically robust data can be easily obtained because microplates enable up to 12 replicate measurements of each sample in a row with a total volume not higher than required for one measurement in a $1 \mathrm{~cm}$ cell. Finally, the preparation of replicate samples may be done with standard 8-12 channel micropipettes, which additionally saves time in sample preparation. Hence, the sensing plate is a rapid screening tool before applying more advanced and timeconsuming chromatographic or electrophoretic methods for separation and quantitation of specific BAs.

Pyrylium ions are heterocyclic aromatic compounds that react under mild conditions with amino groups by exchange of oxygen with the amidic nitrogen. The dye used in the sensing microplates is the 2,6-dimethyl-4-[(E)-2-(2,3,6,7-tetrahydro- $1 H, 5 H$-pyrido [3,2,1-ij]quinolin-9-yl)-vinyl]-pyranylium ion (Py-1). It offers one of the smallest blue and fluorescent chromophores known, since the reactive pyrylium group is a part of the chromophoric system. The Py-1 dye exclusively reacts with primary amines and primary amino groups of proteins ${ }^{26-28}$ to yield a red pyridinium product. This is accompanied by a shortwave shift of the absorbance from $620 \mathrm{~nm}$ to about $502 \mathrm{~nm}$ (from blue to red). The red product shows strong fluorescence (quantum yield $(\phi)$ up to 0.5 ) whereas $\phi$ of the blue form is well below 0.01 . This enables the product to be fluorescently quantified in the presence of unreacted dye.

Three procedures that seemed suitable for extraction of amines from seafood samples were evaluated. The first one was the A.O. A.C. official method (977.13) for histamine, ${ }^{29}$ the second one was a trichloroacetic acid-based (TCA) method, ${ }^{30}$ and the third one was the A.O.A.C. method 35.1.32, a methanolic extraction procedure. ${ }^{31}$ The first two methods are not suitable for determination of BAs with the sensing plate because the extract itself is too acidic to enable direct determination in the plate. Here, the pyrylium ring of Py-1 is destroyed yielding an orange color of the sensing spots (see Fig. S2 $\dagger$ ). Alkalinization to adjust a certain $\mathrm{pH}$ following extraction was regarded too tedious as we intended to develop an overall rapid and simple sample preparation. The methanolic extraction procedure, however, works best in that it is rapid, simple, and eliminates the interference of proteins. Proteins denature and precipitate in methanol and can be removed during the filtration steps. Moreover, the pretreatment at $60{ }^{\circ} \mathrm{C}$ for $30 \mathrm{~min}$ will render them insoluble by aggregation and denaturation. Furthermore, Hypan has been found to efficiently shield Py-1 from proteins (and labeling reactions with their lysine side-chains) in sensing layers. ${ }^{32,34}$ Unlike in a cocktail for determination of BAs with test stripes, ${ }^{34}$ no additional dye for referencing of the fluorescence signal is required in the sensing plates. No decomposition of the sensing spots over $1 \mathrm{~h}$ was observed after adding the methanolic extracts.

\section{Visible readout, linear range and limits of detection}

Representatives of aliphatic, aromatic, and heteroaromatic biogenic amines (mono- and polyamines) were selected to demonstrate that the sensing plate will work with various kinds of biogenic primary amines. The calibration curves for determination of the biogenic amines were acquired by fluorescence readout of the sensing plates. Tyramine, histamine, spermidine, putrescine, 1-tetradecylamine, and benzylamine were tested in the range of $0-100 \mu \mathrm{g} \mathrm{mL}^{-1}$. Calibration curves were acquired for each biogenic amine in methanol using at least five increasing concentrations in five replicates.

Increasing concentrations of histamine result in a color gradient depending on the amine concentration (see Fig. 1). On going from deep blue in the absence of histamine, a blue-greenish color is seen after adding $1 \mu \mathrm{g} \mathrm{mL}^{-1}$ of histamine that becomes deep green at higher amine concentrations, changes to green-red at around $30 \mu \mathrm{g} \mathrm{mL}^{-1}$ and turns to bright red at $50 \mu \mathrm{g} \mathrm{mL}^{-1}$ and higher concentrations.

Concentrations of clinical relevance $(0.3-1 \mathrm{mM})$ which may induce symptoms of poisoning can be well addressed. ${ }^{32}$ For histamine, $0.3 \mathrm{mM}$ corresponds to $33 \mu \mathrm{g} \mathrm{mL}^{-1}$, i.e. the borderline between the deep green color and the appearance of the first visible red color in Fig. 1. Hence, the change of color is distinct enough even to enable a semi-quantitative sample readout on potential toxicity by eye-vision. A red color can then be understood as the warning color for a potentially poisoning sample. Higher concentrations of histamine yield an even brighter red color. This makes the sensing plate a viable tool to determine biogenic amines in samples below the odor threshold for BAs of the human nose $(<1 \mathrm{mM})$. $^{33}$

The luminescence-based calibration curve for histamine has a sigmoidal shape (Fig. 2). The linear range is $0.2-60 \mu \mathrm{g} \mathrm{mL}-1$ $\left(r^{2}=0.998, n=5\right)$ as shown in the inset of Fig. 2 and in Table 1.

The linear range for tyramine, putrescine, and spermidine is $0.50-40 \mu \mathrm{g} \mathrm{mL}^{-1}$, for 1-tetradecylamine the linearity was in the range from 0.60 to $30 \mu \mathrm{g} \mathrm{mL}^{-1}$ and for benzylamine the linearity was in the range $0.30-20 \mu \mathrm{g} \mathrm{mL}^{-1}$ (Table 1). This corresponds to linear calibration ranges of on average of 2.5 decades. The squares of the correlation coefficients vary between 0.985 and 0.999 , which is excellent for a rapid screening method. The sensitivity, as indicated by the slopes, towards the various BAs varies (not unexpectedly) by a factor of 2.5. The close similarity of the linear ranges of all amines suggests determination of the total amount of BAs in real samples. The limits of detection (LODs) have been determined based on calibration curves using $\mathrm{LOD}=3 \sigma /$ slope. The LODs are found in the range of $0.16-0.56$ $\mu \mathrm{g} \mathrm{mL}^{-1}(1.4-3.4 \mu \mathrm{M})$. All calibration data for the biogenic amines are summarized in Table 1 . These LODs are 6-70-fold lower than those found recently for sensing stripes. ${ }^{34}$ For a $\mathrm{CE}$ 


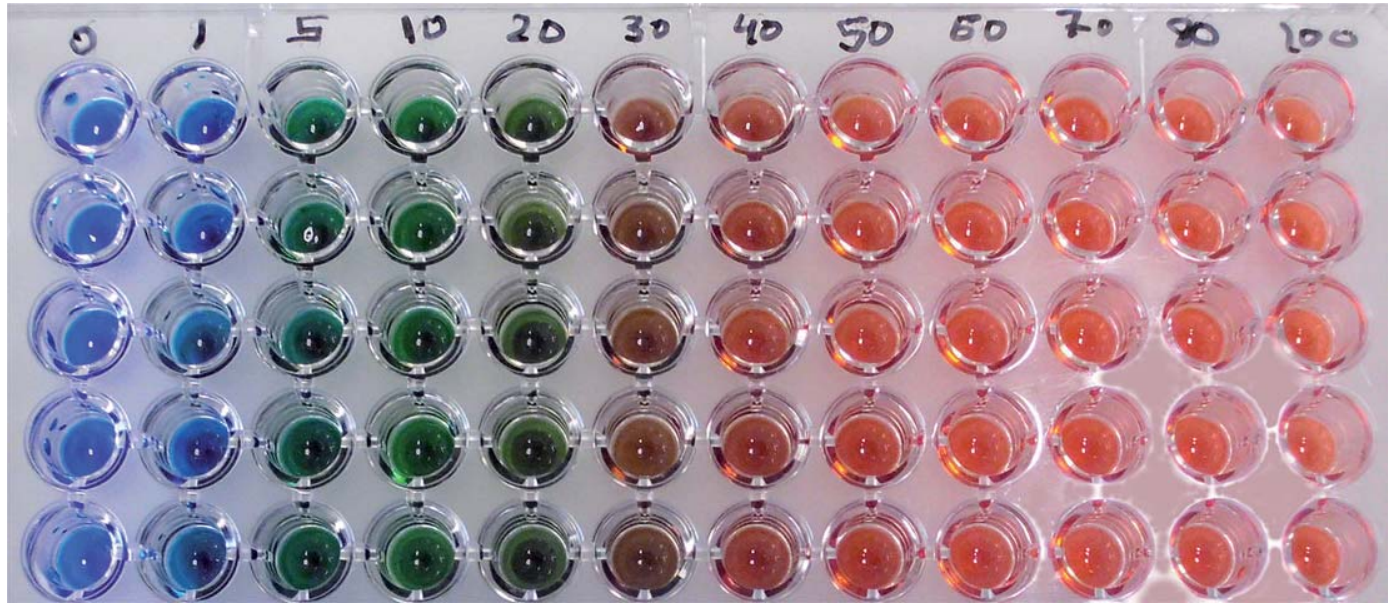

Fig. 1 Image of a sensing microplate reacted with various concentrations of histamine (the numbers indicate the concentrations of histamine in $\mu \mathrm{g}$ $\left.\mathrm{mL}^{-1}\right)$.

method, ${ }^{19}$ the linear range was from 0.11 to $11.1 \mu \mathrm{g} \mathrm{mL}{ }^{-1}$ for all biogenic amines (Table 2), with similar correlation coefficients (ranging from 0.979 to 0.995 ). While the lower limit of the linear range is comparable to that of the sensing plate, the plate can reach concentrations up to 5-fold higher (of histamine) than $\mathrm{CE}$. The LOD (at $S / N=3$ ) for his of the CE method is slightly lower $\left(0.017 \mu \mathrm{g} \mathrm{mL}^{-1}\right)$. CE, however, allows sensing in high throughput with very expensive instrumentation, only.

For GC-MS, ${ }^{20}$ the linear range was up to $100 \mu \mathrm{g} \mathrm{g}^{-1}$ and the LOD is at $5 \mu \mathrm{g} \mathrm{g}^{-1}$ of histamine. HPLC showed superior performance ${ }^{18}$ with the linear range being up to $130 \mu \mathrm{g} \mathrm{mL}^{-1}$. The LOD is $0.051 \mu \mathrm{g} \mathrm{mL}^{-1}$. HPLC, however, requires more expensive equipment which (compared to a sensing plate) has no highthroughput capability and does not enable semi-quantitative evaluation by eye-vision.

For an enzyme sensor array, ${ }^{22}$ the lower detection limits were 2 $\mu \mathrm{g} \mathrm{mL}{ }^{-1}$ for histamine with a linear range up to $40 \mu \mathrm{g} \mathrm{mL}^{-1}$. However, the mean correlation coefficient of 0.854 is moderate.
By comparing the above methods to our sensing plate (Table 2), we found that the linear range of our sensing plate is broader than that of CE, GC-MS and the enzyme sensing array. This is advantageous as no further dilution steps are required for the majority of the samples. Moreover, the sensing plate combines HTS-capability and semi-quantitative evaluation by eye-vision. The detection limits reached by the sensing plate are by far sufficient to study biogenic amine concentrations in food (see the later section).

\section{Response time}

Response time is the amount of time required for a sensor to respond (almost) completely to a change in input. To determine the response time of the sensing plate, we measured the fluorescence intensity of the sensing plate after injection of various concentrations of histamine at $5 \mathrm{~min}$ to $60 \mathrm{~min}$ in increments of $5 \mathrm{~min}$.

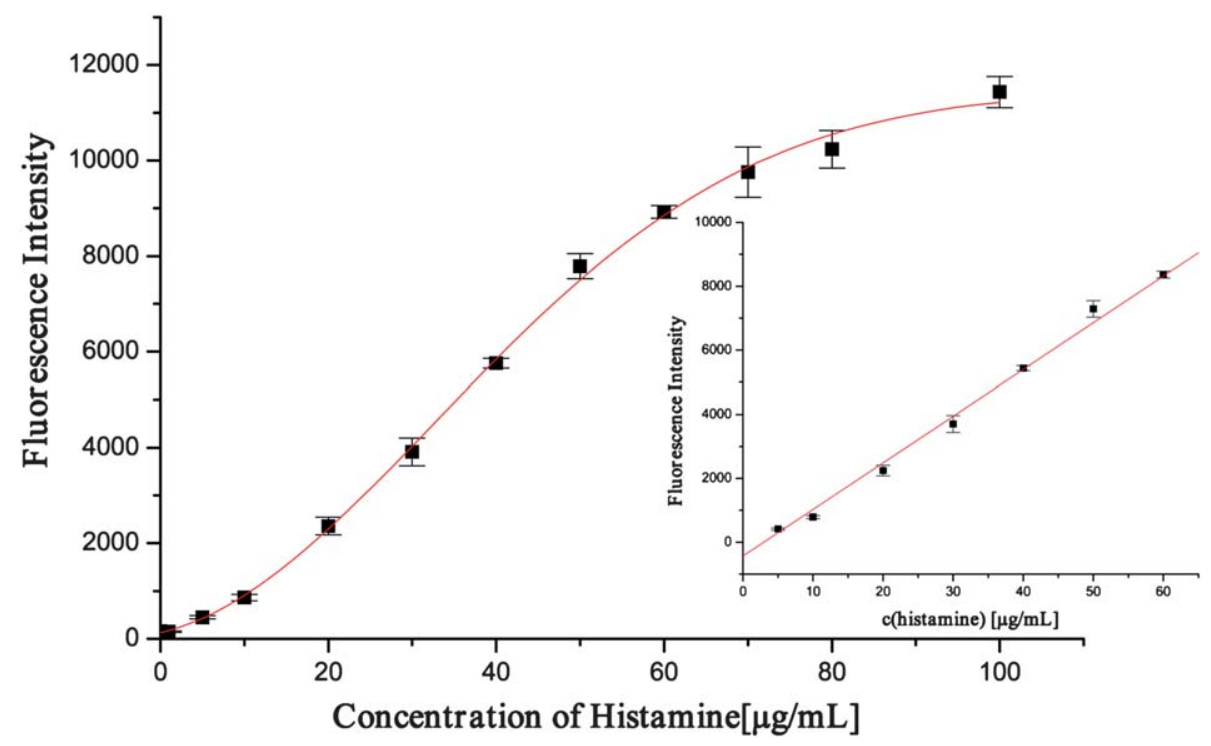

Fig. 2 Calibration plot (error bars indicate standard deviations) for determination of histamine in sensing plates and linear range (inset). 
Table 1 Linear range, regression equation, correlation coefficients, RSDs and LODs for determination of biogenic amines with sensing microplates

\begin{tabular}{|c|c|c|c|c|c|c|}
\hline Amine & Regression equation & $R^{2}$ & $\begin{array}{l}\text { RSD } \\
(\%, n=5)\end{array}$ & $\begin{array}{l}\mathrm{LOD} / \\
\mu \mathrm{g} \mathrm{mL}^{-1}\end{array}$ & $\begin{array}{l}\mathrm{LOD} / \\
\mu \mathrm{mol} \mathrm{L}\end{array}$ & $\begin{array}{l}\text { Linear } \\
\text { range/ } \mu \mathrm{g} \mathrm{mL}^{-1}\end{array}$ \\
\hline Histamine & 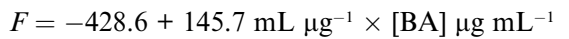 & 0.998 & 2.79 & 0.16 & 1.4 & $0.2-60$ \\
\hline Putrescine & 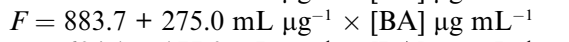 & 0.991 & 0.983 & 0.30 & 3.4 & $0.5-40$ \\
\hline Tyramine & 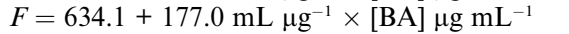 & 0.985 & 1.24 & 0.47 & 3.4 & $0.5-40$ \\
\hline 1-Tetradecylamine & 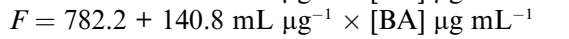 & 0.997 & 0.923 & 0.59 & 2.8 & $0.6-30$ \\
\hline Benzylamine & 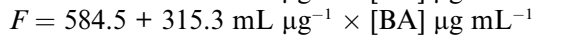 & 0.999 & 1.00 & 0.26 & 2.4 & $0.3-20$ \\
\hline
\end{tabular}

Fig. 3 illustrates that even after 5 min, most of the fluorescence increase already has occurred. Further on, only a very modest increase of fluorescence intensity is observed over time for each concentration of histamine. As we intended to develop a rapid sensing microtiter plate for biogenic amines, the optimum response time for the measurement was chosen to be $10 \mathrm{~min}$, where about $75 \%$ of the total signal change (within $1 \mathrm{~h}$ ) is achieved for most concentrations. The chromatographic methods and the sensing array have long sampling times (23-150 min per sample, Table 2), whereas one sensing plate (96 samples) only requires $10 \mathrm{~min}$ incubation and $2 \mathrm{~min}$ for data readout (or one eye-view for semi-quantitative evaluation).

\section{Testing of conceivable interferents}

The effect of the interference of proteins can be neglected due to the methanolic extraction. The pretreatment at $60^{\circ} \mathrm{C}$ for $30 \mathrm{~min}$ will render them insoluble by aggregation and denaturation. Further on, they will be removed during the filtration steps. Finally, Hypan has been found to efficiently shield Py-1 from proteins (and labeling reactions with their lysine side-chains) in sensing layers. ${ }^{32,34}$

In organic solvents like methanol, secondary and tertiary amines can nucleophilically attack the pyrylium ring of Py-1. ${ }^{19}$ When present in molar excess, secondary amines react fast by a ring opening reaction, but do not form a new peak in the absorbance spectra. The reaction of tertiary amines is by far slower. Both reactions can be detected by a decrease of absorbance of the label (data not shown) but lead to non-fluorescent products. Py-1 yields fluorescent conjugates with primary amines only.
When Py-1 is embedded in the layer of Hypan polymer in the sensing microplate, the effect of potential interferents is of low significance. The fluorescence of a sample containing $50 \mu \mathrm{g}$ $\mathrm{mL}^{-1}$ of histamine (his) and an interferent was monitored each 5 min for $30 \mathrm{~min}$. The effect of diethylamine (DEA), triethylamine (TEA), cysteine and ammonia at concentrations of 0.1 and $1 \mu \mathrm{g}$ $\mathrm{mL}^{-1}$, respectively, in the presence of his is shown in Fig. 4. In the presence of low concentrations of interferent, almost no effect on the luminescence of his is found after the recommended incubation time of $10 \mathrm{~min}$. At longer incubation times,

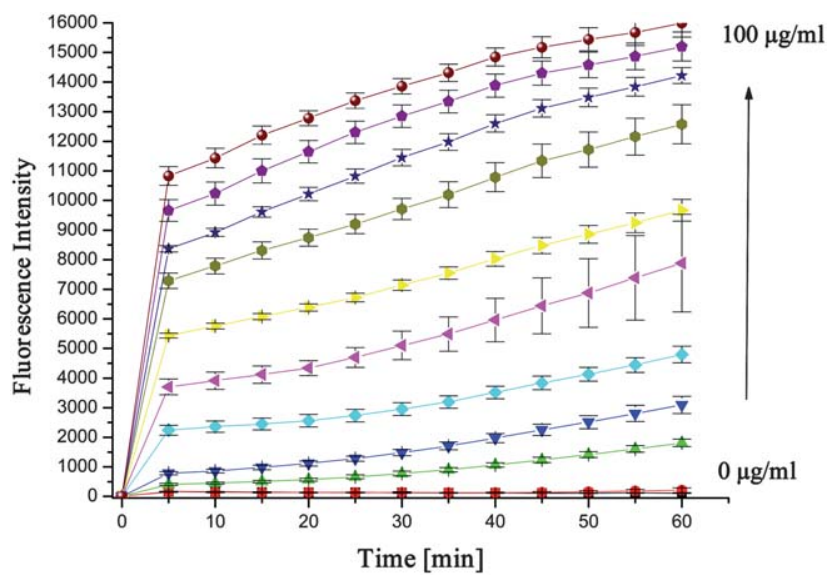

Fig. 3 Kinetic of the reaction of various concentrations of histamine ( 0 , $1,5,10,20,30,40,50,60,80$ and $100 \mu \mathrm{g} \mathrm{mL}^{-1}$, from bottom to top) at $\lambda_{\text {exc/em }}=485 / 620 \mathrm{~nm}$ measured for $1 \mathrm{~h}$ in $5 \mathrm{~min}$ increments in the sensing plate (error bars for $n=3$ ).

Table 2 Figures of merit of selected methods for determination of BAs

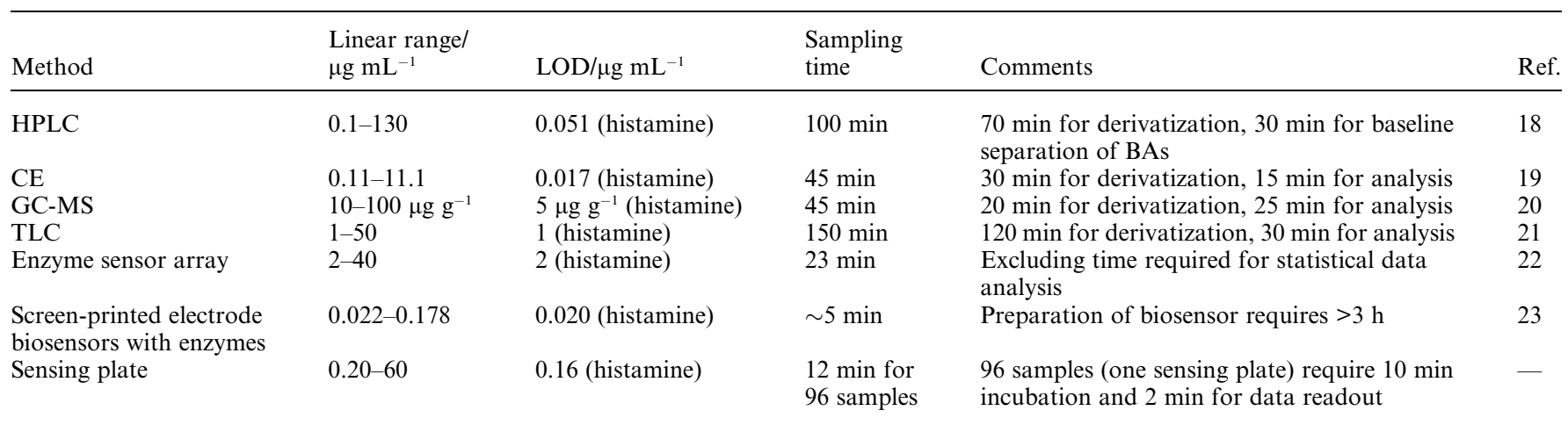




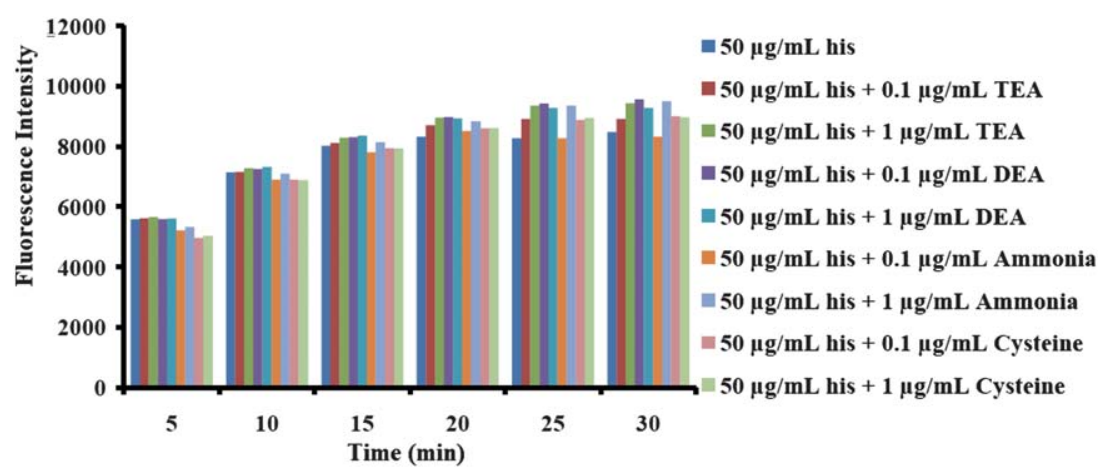

Fig. 4 Fluorescence signal in a sensing plate with DEA, TEA, cysteine and ammonia at concentrations of $0.1 \mu \mathrm{g} \mathrm{mL}-1$ and $1 \mu \mathrm{g} \mathrm{mL}^{-1}$ against a histamine concentration of $50 \mu \mathrm{g} \mathrm{mL}^{-1}$ at different time intervals from $5 \mathrm{~min}$ to $30 \mathrm{~min}$.

a slight fluorescence enhancement due to almost all interferents is seen.

Higher concentrations of interferent (50 and $100 \mu \mathrm{g} \mathrm{mL} \mathrm{m}^{-1}$ ) with respect to his were studied, as shown in Fig. 5. Again, DEA and TEA have almost no effect on the luminescence of his after the recommended incubation time of $10 \mathrm{~min}$. In the presence of higher concentrations of ammonia or cysteine, the fluorescence intensity is higher than that of the reference, however, the enhancement does not alter significantly over the incubation time. Hence, it is advisable to keep the recommended incubation time at $10 \mathrm{~min}$ for the detection of unknown samples in the sensing plate.

\section{Determination of biogenic amines in real samples}

The degree of spoilage of fish was assessed via the concentration of BAs which originate from the activity of microbial enzymes due to decarboxylation of amino acids. Four kinds of seafood (codfish, tuna, salmon and shrimp) were analyzed during their decomposition at room temperature for 5 days via measurements of fluorescence in the sensing plates. Histamine is the major degradation product formed during aging of seafood. ${ }^{34-36} \mathrm{Hence}$, it was regarded to mostly contribute to the signal change detected in the sensing plate. Therefore, the BA content found in the real samples was related to the histamine concentration and was expressed in equivalents of histamine, similarly, as was done by others. ${ }^{23}$ This total amount of amines (TAC) was quantified by spiking $^{20,22,34-36}$ standard solutions of histamine $(5,10,20,30,40$ and $50 \mu \mathrm{g} \mathrm{mL}^{-1}$ ) to the diluted extracts of seafood sample. A comparison of the slopes of the calibration plot of histamine and the spiked sample of fresh codfish revealed almost identical slopes (data not shown). This supports our assumption that histamine is the major species inducing the luminescence increase and hence is a good measure of the total concentration of biogenic amines in the real sample. Therefore, the sensing microplate may be also used to measure biogenic amines in seafood samples directly using the calibration curve established with histamine solution without spiking. The plots for determination of biogenic amines in spiked seafood samples after (a) one day, (b) three days and (c) five days can be found in Fig. S3†. Good recovery data for histamine in real samples were derived from these measurements and can be found in Table 3. Obviously, BAs are initially present in fish samples, and upon prolonged storage a 5-7-fold increase in the amount of biogenic amines is found. Concentrations of clinical relevance $>100$ to $200 \mu \mathrm{g} \mathrm{g}^{-1}$ are found for all kinds of seafood after one day of storage at room temperature. These values are in good agreement to those found for other fish samples. ${ }^{37,38}$ The progress of spoilage found and the increase

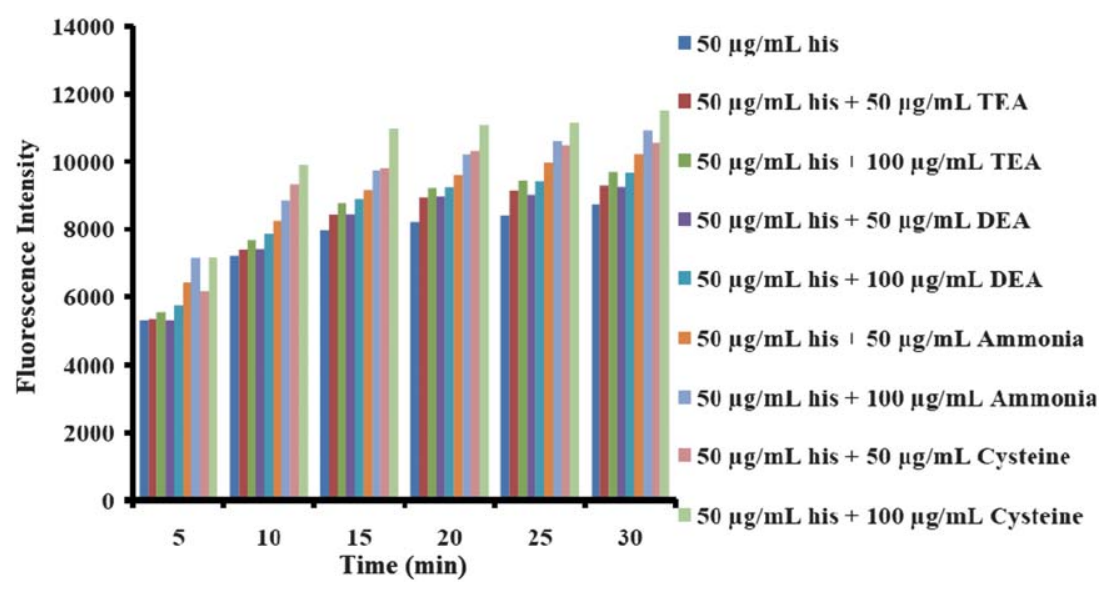

Fig. 5 Fluorescence signal in a sensing plate with DMA, TEA, cysteine and ammonia at concentrations of 50 and $100 \mu \mathrm{g} \mathrm{mL}-1$ against a histamine concentration of $50 \mu \mathrm{g} \mathrm{mL}^{-1}$ at different time intervals from $5 \mathrm{~min}$ to $30 \mathrm{~min}$. 
Table 3 Recovery data of contents of biogenic amines (TAC) in real samples, expressed as equivalents of histamine

\begin{tabular}{|c|c|c|c|c|c|c|}
\hline $\begin{array}{l}\text { Real } \\
\text { sample }\end{array}$ & Day & $\begin{array}{l}\text { Dilution } \\
\text { factor }\end{array}$ & $\begin{array}{l}\text { Histamine } \\
\text { added/ } \\
\mu \mathrm{g} \mathrm{mL}^{-1}\end{array}$ & $\begin{array}{l}\text { TAC found, } \\
\text { accounted } \\
\text { for dilution/ } \\
\mu \mathrm{g} \mathrm{mL}^{-1}\end{array}$ & $\begin{array}{l}\text { Recovery } \\
(\%)\end{array}$ & $\begin{array}{l}\text { TAC, } \\
\text { accounted } \\
\text { for dilution/ } \\
\mu \mathrm{g} \mathrm{g}^{-1} \\
\end{array}$ \\
\hline \multirow[t]{14}{*}{ Tuna } & \multirow[t]{2}{*}{1} & \multirow[t]{2}{*}{10} & 0 & 15.80 & - & 158 \\
\hline & & & 10 & 25.21 & 97.7 & 252.2 \\
\hline & \multirow[t]{6}{*}{3} & \multirow[t]{6}{*}{40} & 0 & 24.86 & - & 248.6 \\
\hline & & & 10 & 35.06 & 102.0 & 350.6 \\
\hline & & & 20 & 43.68 & 94.1 & 436.8 \\
\hline & & & 30 & 57.18 & 107.7 & 571.8 \\
\hline & & & 40 & 68.15 & 108.2 & 681.5 \\
\hline & & & 50 & 74.94 & 100.1 & 749.4 \\
\hline & \multirow[t]{6}{*}{5} & \multirow[t]{6}{*}{40} & 0 & 75.40 & - & 754 \\
\hline & & & 10 & 85.02 & 96.2 & 850.2 \\
\hline & & & 20 & 95.20 & 99.0 & 952 \\
\hline & & & 30 & 105.82 & 101.4 & 1058.2 \\
\hline & & & 40 & 115.28 & 99.7 & 1152.8 \\
\hline & & & 50 & 126.22 & 101.6 & 1262.2 \\
\hline \multirow[t]{14}{*}{ Codfish } & \multirow[t]{2}{*}{1} & \multirow[t]{2}{*}{40} & 0 & 22.40 & - & 224 \\
\hline & & & 10 & 34.34 & 106.0 & 343.4 \\
\hline & \multirow[t]{6}{*}{3} & \multirow[t]{6}{*}{40} & 0 & 46.70 & - & 467 \\
\hline & & & 10 & 56.91 & 102.1 & 569.1 \\
\hline & & & 20 & 67.07 & 101.9 & 670.7 \\
\hline & & & 30 & 78.39 & 105.6 & 783.9 \\
\hline & & & 40 & 88.08 & 103.4 & 880.8 \\
\hline & & & 50 & 97.84 & 102.2 & 978.4 \\
\hline & \multirow[t]{6}{*}{5} & \multirow[t]{6}{*}{100} & 0 & 148.4 & - & 1484 \\
\hline & & & 10 & 151.3 & 95.5 & 1513 \\
\hline & & & 20 & 168.88 & 102.4 & 1688.8 \\
\hline & & & 30 & 178.90 & 101.7 & 1789 \\
\hline & & & 40 & 189.29 & 102.3 & 1892.9 \\
\hline & & & 50 & 199.86 & 102.9 & 1998.6 \\
\hline \multirow[t]{14}{*}{ Salmon } & \multirow[t]{2}{*}{1} & \multirow[t]{2}{*}{50} & 0 & 25.84 & - & 258.4 \\
\hline & & & 10 & 34.32 & 95.8 & 343.2 \\
\hline & 3 & 50 & 0 & 58.80 & - & 588 \\
\hline & & & 10 & 68.65 & 98.5 & 686.5 \\
\hline & & & 20 & 82.34 & 117.7 & 823.4 \\
\hline & & & 30 & 94.22 & 118.1 & 942.2 \\
\hline & & & 40 & 105.09 & 115.7 & 1050.9 \\
\hline & & & 50 & 110.83 & 104.0 & 1108.3 \\
\hline & 5 & 100 & 0 & 124.6 & - & 1246 \\
\hline & & & 10 & 134.5 & 107.9 & 1345 \\
\hline & & & 20 & 148.98 & 121.9 & 1490 \\
\hline & & & 30 & 158.71 & 113.7 & 1588 \\
\hline & & & 40 & 169.47 & 112.2 & 1694.7 \\
\hline & & & 50 & 175.62 & 102.0 & 1756.2 \\
\hline Shrimp & 1 & 20 & 0 & 14.57 & - & 145.7 \\
\hline & & & 5 & 18.74 & 95.8 & 187.4 \\
\hline & 3 & 40 & 0 & 75.50 & - & 755 \\
\hline & & & 10 & 88.9 & 117.8 & 889 \\
\hline & & & 20 & 97.87 & 111.8 & 978.6 \\
\hline & & & 30 & 107.87 & 107.9 & 1079 \\
\hline & & & 40 & 114.02 & 96.3 & 1140 \\
\hline & & & 50 & 120.37 & 89.7 & 1203.7 \\
\hline & 5 & 80 & 0 & 141.1 & - & 1411 \\
\hline & & & 10 & 150.8 & 96.9 & 1508 \\
\hline & & & 20 & 133.15 & 95.2 & 1332 \\
\hline & & & 30 & 143.39 & 97.7 & 1434 \\
\hline & & & 40 & 157.55 & 108.6 & 1575 \\
\hline & & & 50 & 168.48 & 108.8 & 1685 \\
\hline
\end{tabular}

of the total amine content of the seafood samples correlate with previous data on TAC determination in fish. ${ }^{37,38}$

\section{Conclusion}

A fast and reliable sensing microplate to screen biogenic amines in food samples was developed. BAs can be quantified visually by a color change from blue over green to red where the red color indicates a potentially toxic concentration of BA. Fluorescence measurement enables determination at concentrations well below the odor threshold of the human nose. Seafood samples can be successfully evaluated either directly or by the standard addition method without interference of protein after a simple methanolic extraction. BAs can be determined with a limit of detection down to $0.16 \mu \mathrm{g} \mathrm{mL} \mathrm{m}^{-1}(1.4 \mu \mathrm{M})$. This suggests further determination of BAs in cheese or in drinking water samples, where lower concentrations are commonly found.

\section{Acknowledgements}

G.M.K. and M.-S.S. thank the German Egyptian Research Fund (GERF) for a grant within the project EGY08/004.

\section{References}

1 A. Önal, Food Chem., 2007, 103, 1475-1486.

2 B. S. Hwang, J. T. Wang and Y. M. Choong, Food Chem., 2003, 82, 329-334.

3 W. X. Du, C. M. Lin, A. T. Phu, J. A. Cornell, M. R. Marshall and C.-I. Wei, J. Food Sci., 2002, 67, 292-301.

4 E. K. Paleologos and M. G. Kontominas, Anal. Chem., 2004, 76, $1289-1294$.

5 M. T. Veciana Nogue, A. Marine Font and M. C. Vidal Carou, J. Agric. Food Chem., 1997, 45, 2036-2041.

6 M. L. Wu, C. C. Yang, C. Y. Yang, J. Ger and J. F. Deng, Vet. Hum. Toxicol., 1997, 39, 236-241.

7 A. R. Shalaby, Food Res. Int., 1996, 29, 675-690.

8 B. Garcia-Acosta, M. Comes, J. L. Bricks, M. A. Kudinova, V. V. Kurdyukov, A. I. Tolmachev, A. B. Descalzo, M. D. Marcos, R. Martinez-Manez, A. Moreno, F. Sancenon, J. Soto, L. A. Villaescusa, K. Rurack, J. M. Barat, I. Escriche and P. Amoros, Chem. Commun., 2006, 2239-2241.

9 M. L. Latorre-Moratalla, J. Bosch-Fuste, T. Lavizzari, S. Bover-Cid, M. T. Veciana-Nogues and M. C. Vidal-Carou, J. Chromatogr., A, 2009, 1216, 7715-7720.

10 J. Leszczynska, M. Wiedlocha and U. Pytasz, Czech J. Food Sci., 2004, 22, 81-86.

11 P. Kalac, J. Savel, M. Krizek, T. Pelikanova and M. Prokopova, Food Chem., 2002, 79, 431-434.

12 A. Y. Smit, W. J. du Toit and M. du Toit, S. Afr. J. Enol. Vitic., 2008, 29, 109-127.

13 R. Romero, M. Sanchez-Vinas, D. Gazquez and M. Gracia Bagur, J. Agric. Food Chem., 2002, 50, 4713-4717.

14 A. A. Tameem, B. Saad, A. Makahleh, A. Salhin and M. I. Saleh, Talanta, 2010, 82, 1385-1391.

15 G. Duflos, C. Dervin, S. Bouquelet and P. Malle, J. AOAC Int., 1999, 82, 1097-1101.

16 J. E. Straton, R. W. Huttkins and S. L. Taylop, J. Food Prot., 1991, 54, $460-470$.

17 M. Fonberg-Broczek, B. Windyga, J. Kozlowski, D. SawilskaRautenstrauch and S. Kahl, Roczn. PZH, 1988, 39, 226-230.

18 M. Saaid, B. Saad, N. H. Hashim, A. S. M. Ali and M. I. Saleh, Food Chem., 2009, 113, 1356-1362.

19 M.-S. Steiner, R. J. Meier, C. Spangler, A. Duerkop and O. S. Wolfbeis, Microchim. Acta, 2009, 167, 259-266.

20 H. S. Marks and C. R. Anderson, J. AOAC Int., 2006, 89, 1591-1599.

21 J. Lapa-Guimaraes and J. Pickova, J. Chromatogr., A, 2004, 1045, $223-232$.

22 J. Lange and C. Wittmann, Anal. Bioanal. Chem., 2002, 372, 276-283.

23 M. A. Alonso-Lomillo, O. Dominguez-Renedo, P. Matos and M. J. Arcos-Martinez, Anal. Chim. Acta, 2010, 665, 26-31.

24 L. Byrne, K. T. Lau and D. Diamond, Analyst, 2002, 127, 1338-1341.

25 A. Pacquit, K. T. Lau, H. McLaughlin, J. Frisby, B. Quilty and D. Diamond, Talanta, 2006, 69, 515-520.

26 B. K. Wetzl, S. M. Yarmoluk, D. B. Craig and O. S. Wolfbeis, Angew. Chem., Int. Ed., 2004, 43, 5400-5402. 
27 D. B. Craig, B. K. Wetzl, A. Dürkop and O. S. Wolfbeis, Electrophoresis, 2005, 26, 2208-2213.

28 R. J. Meier, M.-S. Steiner, A. Duerkop and O. S. Wolfbeis, Anal. Chem., 2008, 80, 6274-6279.

29 C. den Brinker, C. Rayner and M. Kerr, J. AOAC Int., 1990, 73, 876877.

30 L. S. Moret and S. Conte, J. Chromatogr., A, 1996, 729, 363369.

31 AOAC, Official Methods of Analysis, AOAC, Washington, 16th edn, 1995, (Method 35.1.32).

32 A. V. Stoy, J. Biomater. Appl., 1998, 3, 552-604.
33 T. L. Nelson, I. Tran, T. G. Ingallinera, M. S. Maynor and J. J. Lavigne, Analyst, 2007, 132, 1024-1030.

34 M.-S. Steiner, R. J. Meier, A. Duerkop and O. S. Wolfbeis, Anal. Chem., 2010, 82, 8402-8405.

35 M. S. Maynor, T. L. Nelson, C. O'Sullivan and J. J. Lavigne, Org. Lett., 2007, 9, 3217-3220.

36 D.-F. Hwang, S.-H. Chang, C.-Y. Shiau and C.-C. Cheng, J. Food Sci. 1995, 60, 926-928.

37 M. Niculescu, C. Nistor, I. Frébort, P. Peč, B. Mattiasson and E. Csöregi, Anal. Chem., 2000, 72, 1591-1597.

38 G. C. Chemnitius and U. Bilitewski, Sens. Actuators, B, 1996, 32, 107-113. 